\title{
Sociodemographic Factors Correlating With The Use of Complementary and Alternative Medicine Among Ethiopian Immigrants in The USA
}

\author{
Fekadu Fullas $^{\text {1* }}$, Bisrat Hailemeskel ${ }^{2}$, Anteneh Habte ${ }^{3}$, La'Marcus T Wingate $^{2}$ \\ ${ }^{1}$ UnityPoint Health-St. Luke’s, Pharmacy Department, 2720 Stone Park Boulevard, Sioux City, IA 51104, USA \\ ${ }^{2}$ College of Pharmacy, Howard University, $23004^{\text {th }}$ Street, N.W., Washington DC, 20059, USA \\ ${ }^{3}$ Veterans Affairs Medical Center, Martinsburg, WV 25405; West Virginia University School of Medicine, Harpers \\ Ferry, WV 25405, USA
}

*Corresponding Author: Fekadu Fullas, Pharmacy Department, UnityPoint Health-St. Luke’s, 2720 Stone Park Blvd, Sioux City, IA 51104, USA; Tel 712-266-6156; E-mail: Fekadu.Fullas@unitypoint.org

Received: 21 March 2018; Accepted: 05 April 2018; Published: 09 April 2018

\begin{abstract}
Objective: To determine sociodemographic factors that help to predict the use of complementary and alternative medicine (CAM) by Ethiopian immigrants in the USA.
\end{abstract}

Methods: A multicomponent survey was administered to over 350 Ethiopian immigrants to elicit information regarding their demographic characteristics and use of CAM. The primary dependent variable was use of CAM within the past 5 years. Descriptive statistics were utilized to characterize the sample in regards to gender, age, education, income and length of residency in the USA. Bivariate logistic regression analysis was used to determine which factors were associated with use of CAM. Multivariate logistic regression was utilized to evaluate which characteristics predicted use of CAM after adjusting for other variables.

Results: A bivariate logistic regression analysis of CAM use among Ethiopian immigrants in the USA showed that females were twice as likely as males to use herbs and supplements. Survey participants with some college or associate degree level education had 2.21 times greater odds for using herbs and supplements than those with only high school education. No association was discerned between herbs/supplements use and the categories of age and length of residency in the USA. In a multivariate logistic regression analysis, gender, some college level education and annual income greater than $\$ 100,000$ showed significant association with the use of herbs and supplements.

Conclusion: Certain demographic characteristics such as gender, education and income can be useful in helping to predict which Ethiopian immigrants are more likely to use CAM. 
Keywords: CAM; Ethiopian immigrants in the USA; Sociodemographic characteristics; Regression analysis

\section{Introduction}

Various studies have reported the use of CAM among immigrant communities in the USA. Wu, et al [1] analyzed the pattern of Traditional Chinese Medicine (TCM) use among 198 Chinese patients from data obtained at two San Francisco community clinic sites. In the sample population, patient characteristics such as age, gender, educational level, years spent in the USA were analyzed [1]. A larger study was done on CAM use among 3,258 Chinese and Vietnamese Americans from data collected at 11 community health centers spread in eight cities across USA [2]. The study investigated TCM use pattern by socio-demographic categories. Similar studies have also been reported for Hispanic [3], Latino [4], Asian Indian [5] immigrants, as well as for multi-ethnic patients [6].

In two previous communications, we reported the results of a survey on the use of CAM among Ethiopian immigrants in the USA [7,8]. Of 206 survey respondents who used herbs and supplements, 180 also used one or more other CAM modalities, such as prayer, holy water, acupuncture, massage, incense burning, traditional manipulation (wegesha), chiropractice and biofeedback [7]. However, no information is available in the literature on the relationship of sociodemographic factors and the use of CAM among Ethiopian immigrants in the USA. In this paper, we explore the association between age, gender, educational level, income and length of residency in the USA and use of herbal products and supplements.

\section{Methods}

This study employed a cross sectional design to evaluate factors that were associated with use of herbs and supplements among Ethiopian immigrants in the United States. A pilot survey was designed to elicit information concerning the patterns of CAM use in the population of interest. The questionnaire was piloted among a small sample of randomly selected immigrants from Ethiopia who provided constructive feedback. The suggestions were synthesized to compose the survey administered to Ethiopian immigrants as a part of the study. Flyers describing the purpose of the study were placed at strategic locations with the greater Washington DC metropolitan area to promote participation of local Ethiopians. Additionally, flyers advertising the study were placed on several internet sites appealing to diverse ethnic audiences such as the People to People Inc. website. Formal invitations to complete the survey were extended to a total of nearly 700 eligible contacts that were obtained from the People to People website. Survey responses were collected from April 13 to August 31 of 2016 with the majority of the data being collected via SurveyMonkey ${ }^{\circledR}$. A small fraction of the survey was administered face to face using paper forms. The study was approved by the Institutional Review Board at Howard University.

The primary dependent variable was self-reported use of supplements or herbal products within the past five years. Relevant independent variables included gender, age, education, annual family income, and length of residency in the U.S. Descriptive statistics were employed in order to describe the sample in terms of sociodemographic characteristics. Bivariate logistic regression was utilized to explore whether the independent variables were associated with the outcome variable. A multivariate logistic regression was utilized in order to determine which 
factors predicted use of CAM after adjusting for the other variables. All analyses were conducted using SPSS version 24.

\section{Results}

A total of 700 individuals were invited to complete the study, out of which 355 provided usable responses. Nearly $61 \%$ of survey respondents were males (Table 1). Approximately $40 \%$ of respondents were 40 or younger, and nearly $44 \%$ of the respondents were 41 to 60 . The vast majority of the sample had at least some college experience and approximately $62 \%$ had at least a bachelor's degree. Approximately $39 \%$ of the sample population had an annual family income of less than $\$ 50,000$, while nearly $30 \%$ of respondents indicated that their family income was higher than $\$ 100,000$. The majority of respondents had been in the U.S. for longer than 15 years and about $58 \%$ of this group indicated that they had used herbs or supplements within the past five years.

Table 1: Demographic and social characteristics of Ethiopian immigrant respondents*

\begin{tabular}{|c|c|c|c|}
\hline Variable & $\begin{array}{l}\text { Overall Sample } \\
(n=355)\end{array}$ & $\begin{array}{l}\text { Reporting CAM Use } \\
(n=206)\end{array}$ & Prevalence of CAM use \\
\hline & Frequency (N) [\%] & Frequency $(\mathrm{N})$ & Percentage (\%) \\
\hline \multicolumn{4}{|l|}{ Gender } \\
\hline NR & $5(1.4)$ & 3 & 60.0 \\
\hline Male & $215(60.6)$ & 111 & 51.6 \\
\hline Female & $135(38.0)$ & 92 & 68.1 \\
\hline \multicolumn{4}{|l|}{ Age } \\
\hline NR & $3(0.8)$ & 3 & 100 \\
\hline 18 to 40 & $140(39.4)$ & 82 & 58.6 \\
\hline 41 to 60 & $156(43.9)$ & 91 & 58.3 \\
\hline Over 60 & $56(15.8)$ & 30 & 53.6 \\
\hline \multicolumn{4}{|l|}{ Education 1 (referent) } \\
\hline NR & $6(1.7)$ & 3 & 50.0 \\
\hline Up to high school diploma or GED & $45(12.7)$ & 20 & 44.4 \\
\hline Some college or associate's degree & $83(23.4)$ & 53 & 63.9 \\
\hline Bachelor's degree or higher & $221(62.3)$ & 130 & 58.8 \\
\hline \multicolumn{4}{|l|}{ Annual Family Income } \\
\hline NR & $10(2.8)$ & 3 & 30.0 \\
\hline$\$ 0$ to $\$ 50,000$ & $140(39.4)$ & 88 & 62.9 \\
\hline$\$ 50,001$ to $\$ 100,000$ & $100(28.2)$ & 63 & 63.0 \\
\hline Above $\$ 100,000$ & $105(29.6)$ & 52 & 49.5 \\
\hline
\end{tabular}




\begin{tabular}{|l|l|l|l|}
\hline Length of residency in U.S. & & & \\
\hline NR & $6(1.7)$ & 3 & 50.0 \\
\hline Less than 5 years & $60(16.9)$ & 32 & 53.3 \\
\hline 6 to 15 years & $103(29.0)$ & 62 & 60.2 \\
\hline More than 15 years & $186(52.2)$ & 109 & 58.6 \\
\hline
\end{tabular}

*CAM=Complementary and Alternative Medicine; NR=Not Reported; GED=General Equivalency Diploma; U.S.=United States

In a bivariate logistic regression analysis, the odds of females to report use of herbal products or supplements was 2.00 times greater than males (Table 2). Participants that had some college experience or an associate degree had 2.21 times greater odds to use herbs or supplements when compared to those that had not obtained at least a high school education. In a bivariate analysis, age and length of residency in the USA were determined not to be associated with the use of herbal products or supplements.

Table 2: Binary logistic regression of variables associated with use of herbals or supplements in last 5 years among Ethiopian immigrants to the United States

\begin{tabular}{|c|c|c|}
\hline Sociodemographic characteristics & OR (95\% CI) for Use of Herbals/Supplements & $P$ value* \\
\hline \multicolumn{3}{|l|}{ Gender } \\
\hline Male & 1 (referent) & \\
\hline Female & $2.01(1.28-3.14)$ & $0.002^{*}$ \\
\hline \multicolumn{3}{|l|}{ Age (in years) } \\
\hline 18 to 40 & 1 (referent) & \\
\hline 41 to 60 & $0.99(0.62-1.57)$ & 0.967 \\
\hline Over 60 & $0.82(0.44-1.57)$ & 0.523 \\
\hline \multicolumn{3}{|l|}{ Education } \\
\hline Less than $12^{\text {th }}$ grade to High school diploma or GED & 1 & \\
\hline Some college or associate degree & $2.21(1.06-4.62)$ & $0.036^{*}$ \\
\hline Bachelors or Master’s Degree & $1.79(0.94-3.41)$ & 0.079 \\
\hline \multicolumn{3}{|l|}{ Annual Family Income } \\
\hline$\$ 0$ to $\$ 50,000$ & 1 (referent) & \\
\hline$\$ 50,001$ to $\$ 100,000$ & $1.01(0.59-1.71)$ & 0.982 \\
\hline Above $\$ 100,000$ & $0.58(0.35-0.97)$ & $0.038^{*}$ \\
\hline \multicolumn{3}{|l|}{ Length of time in U.S. } \\
\hline Up to 5 years & 1 (referent) & \\
\hline 6 to 15 years & $1.32(0.70-2.52)$ & 0.393 \\
\hline Over 15 years & $1.24(0.69-2.22)$ & 0.473 \\
\hline
\end{tabular}


CI=Confidence Interval; GED=General Equivalency Diploma; OR=Odds Ratio; U.S.=United States

$* P$ values $<0.05$ are significant.

In a multivariate logistic regression analysis, females had 2.20 times greater odds of using supplements or herbal products after adjusting for other variables (Table 3). In addition, individuals with at least some level of college educations were significantly more likely to use herbs and supplements after adjusting for covariates. Participants with annual family income of over $\$ 100,000$ were significantly less likely to report use of CAM.

Table 3: Multivariate logistic regression of variables associated with use of herbals or supplements in last 5 years among Ethiopian immigrants to the United States

\begin{tabular}{|l|l|l|}
\hline $\begin{array}{l}\text { Sociodemographic } \\
\text { characteristics }\end{array}$ & $\begin{array}{l}\text { AOR (95\% CI) } \\
\text { for Use of Herbals/Supplements }\end{array}$ & P value* \\
\hline Gender & & \\
\hline Male & 1 (referent) & \\
\hline Female & $2.20(1.35-3.58)$ & $0.002^{*}$ \\
\hline Age & & \\
\hline 18 to 40 & 1 (referent) & \\
\hline 41 to 60 & $1.26(0.71-2.21)$ & 0.432 \\
\hline Over 60 & $1.12(0.53-2.34)$ & 0.771 \\
\hline Education & & \\
\hline Less than $12^{\text {th }}$ grade to High school diploma or GED & 1 (referent) & \\
\hline Some college or associate degree & $2.38(1.07-5.29)$ & $0.005^{*}$ \\
\hline Bachelors or Master's Degree & $3.16(1.41-7.08)$ & 0.752 \\
\hline Annual Family Income & & 0.120 \\
\hline \$0 to \$50,000 & 1 (referent) & 0.277 \\
\hline \$50,001 to \$100,000 & $0.67(0.36-1.27)$ & 0.222 \\
\hline Above \$100,000 & $0.35(0.17-0.69)$ & \\
\hline Length of time in U.S. & & 1 (referent) \\
\hline Up to 5 years & $1.77(0.86-3.64)$ & \\
\hline 6 to 15 years & $1.52(0.72-3.21)$ & \\
\hline Over 15 years & & \\
\hline
\end{tabular}

AOR=Adjusted Odds Ratio; CI=Confidence Interval; GED=General Equivalency Diploma; U.S.=United States $* P$ values $<0.05$ are significant. 


\section{Discussion}

Our finding that female survey participants used herbs and supplements more frequently than males is consistent with similar trends reported for Hispanic patients in Indianapolis, IN [3]. According to a national study comprised of 1,824 Asian Indians in the USA, females were 3.3 times more likely to use CAM and 1.8 times more likely to use herbs and dietary supplements [5]. The latter observation is in close alignment with our finding, where females were twice as likely to use CAM than men. It is also consistent with other studies which have shown similar trends [6, 9].

In our survey, we also found an association between level of education and CAM use. However, no question was included to determine if a specific field of study/major influenced the frequency of utilization. In a study released by the U.S. Department of Health and Human Services, it was reported that those with at least some college education were significantly more likely to use CAM than those that had high school education or less [10]. Although this report did not specifically focus on immigrant populations, the finding is strikingly similar to ours. By using a large pool of national data consisting of over 75,000 respondents, Burke et al. determined that respondents with lower educational levels cited lack of knowledge as a reason for non-use of common complementary health practices [11]. No specific question was included in our survey for reasons of non-use of CAM. However, it may be fair to speculate that the same reason could have contributed to non-use among our sample population.

A survey of ethnic minorities in the USA $(n=3,452)$ showed a higher rate of CAM use among female respondents and those having higher educational levels than for males and lower educational levels. Female gender and higher education were predictors of CAM use. Although not significant, those with annual income levels between \$25,000 and 50,000 were slightly higher users than those having lower or higher incomes than this range [12]. A study by Chan and co-workers reported that being female, having higher education and higher income levels were associated with higher rates of CAM use [13]. Our study results are consistent with this finding in regards to gender and higher education levels, but at variance with CAM use and income levels. Unlike the study by Chan et al., our study showed negative association between CAM use and income levels. This can perhaps be explained by a hypothesis that first generation immigrants in general tend to have a low paying job not commensurate with their level of education.

In a large national survey, Eisenberg and co-investigators reported significant association between use of alternative therapies and in turn gender, educational level and income [14]. The study showed that CAM use was more frequent for women, some college level education and annual income levels above $\$ 50,000$ than for survey respondents who are males, have no college education and reported annual income levels less than $\$ 50,000$. This observation is in close agreement with our finding in these categories. With reference to income levels, in a multivariate regression analysis, it was determined that our survey respondents who used CAM at a significantly higher rate had annual incomes between $\$ 50,000$ and 100,000, compared to those with income levels greater than $\$ 100,000(p=0.003)$ [Table 3]. 


\section{Conclusion}

Logistic regression analysis of complementary and alternative medicine (CAM) use among Ethiopian immigrants in the USA showed gender, education level and income to be significant predictors of CAM use. Age and length of residency in the USA did not have significant correlation with the use CAM.

\section{References}

1. Wu APW, Burke A. LeBaron S. Use of traditional medicine by immigrant Chinese patients. Fam Med 39 (2007): 195-200.

2. Ahn AC, Ngo-Metzger Q, Legedza ATR, et al. Complementary and alternative medical therapy use among Chinese and Vietnamese Americans: Prevalence, associated factors, and effects of patient-clinician communication. Am J Public Health 96 (2006): 647-653.

3. Howell H, Kocbbar K, Saywell R, et al. Use of herbal remedies by Hispanic patients: Do they inform their physicians? J Am Board Fam Med 19 (2006): 566-578.

4. Ransford HE, Carrillo FR, Rivera Y. Health-care seeking among Latino immigrants: Blocked access, use of traditional medicine, and the role of religion. J Health Care for the Poor and Underserved. 21 (2010); 862878.

5. Misra R, Balagopal P, Klatt M, et al. Complementary and alternative medicine use among Asia Indians in the United states: A national study. J Altern Complement Med 16 (2010): 843-852.

6. Kuo GM, Hawley ST, Weiss, LT, et al. Factors associated with herbal use among urban multiethnic primary care patients: a cross-sectional survey. BMC Complement Altern Med 4 (2004): 18.

7. Hailemekel B, Fullas F, Habte A, et al. A survey on the use of Complementary and Alternative Medicine among Ethiopian immigrants in the USA. J Complement Med Alt Healthcare 1 (2017): 555568.

8. Hailemeskel B, Fullas F, Habte A, et al. A review of natural remedies commonly used by Ethiopian immigrants in the USA. Curr Res Integr Med 2 (2017): 31-37.

9. Zhang Y, Leach MJ, Hall H, et al. Differences between male and female consumers of complementary and alternative medicine in a national US population: A secondary analysis of 2012 NIHS data. Evidence-based Altern \& Complement Med 2015: 413173.

10. U.S. Department of Health and Human Resources. AARP and National Center for Complementary and Alternative Medicine Survey Report.

https://nccih.gov/sites.nccam.nih.gov/files/news/camstats/2010/NCCAM_aarp_survey.pdf. $\quad$ (accessed March 2018).

11. Burke A, Nahin HL, Stussman BJ. Limited health knowledge as a reason for non-use of four common complementary health practices. PlosONE 10 (2015): e0129336.

12. Mackenzie ER, Taylor L, Bloom BS, et al. Ethnic minority use of complementary and alternative medicine (CAM): A national probability survey of CAM utilizers. Altern Ther Health Med 9 (2003): 50-56.

13. Chan YM, Huang H, Mei H. Socio-economic status, attitudes on use of health information, preventive behaviors, and complementary and alternative medical therapies: Using a U.S. national representative sample. Nat App Sci 3 [2] (2012): 15-23. 
14. Eisenberg DM, Davis RB, Etner SL, et al. Trends in alternative medicine use in the United States, 19901997. JAMA 280 (1998): 1569-1575.

Citation: Fekadu Fullas, Bisrat Hailemeskel, Anteneh Habte, La’Marcus T Wingate. Sociodemographic Factors Correlating With The Use of Complementary and Alternative Medicine Among Ethiopian Immigrants in The USA. J Pharm Pharmacol Res 2 (2018): 024-031.

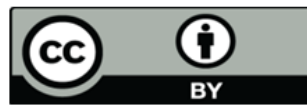

